\title{
Diplomacia, Iglesia y lazos familiares. Las relaciones diplomáticas entre el Perú y la Santa Sede (1859-1887)
}

Julio Abanto

Recibido: 07-ago-20

Aprobado: 10-nov-20

doi: $10.46476 /$ ra.v1i2.51

\section{Sumilla}

La historia política es una disciplina de larga trayectoria en el Perú, pero existe un notable vacío historiográfico sobre las relaciones diplomáticas que sostuvo el Perú con la Santa Sede (Roma) en la segunda mitad del siglo XIX. Por esta razón, se examinará las fuentes históricas procedentes del Archivo del Ministerio de Relaciones Exteriores y de la Biblioteca Nacional del Perú. El objetivo de este trabajo es efectuar un seguimiento a la forma cómo se planteó la política exterior del Estado peruano para alcanzar diversos objetivos nacionales en la Santa Sede. Esto incluye reconstruir los diversos momentos de coordinación entre el Ministerio de Relaciones Exteriores y la legación del Perú en Roma, en la que tiene un rol central la familia Mesones: Luis Mesones y Manuel A. Mesones (18591887), es decir, atraviesan antes y después de la Guerra del Pacífico. Justamente, en este período la alta jerarquía de la Iglesia Católica peruana se convierte en una importante protagonista al asumir diversos cargos en el Estado.

Palabras clave: Relaciones diplomáticas Perú-Santa Sede, Historia de la Iglesia en el Perú, Iglesia Católica, Guerra del Pacífico (1879-1883). 


\section{Abstract}

The discipline of political history has long been practiced in Peru, but there is a notable historiographic gap regarding Peru's diplomatic relations with the Holy See (Rome) during the second half of the nineteenth century. In view of this, historical sources from the archives of the Ministry of Foreign Affairs and the Peruvian National Library will be examined in an effort to trace the ways in which Peru's foreign policy proposed to achieve different national objectives at the Holy See. This includes reconstructing the various moments of coordination between the Ministry of Foreign Affairs and the Peruvian legation in Rome, in which the Mesones family played a central role. Specifically, Luis Mesones and Manuel A. Mesones (1859-1887) continuously occupied the position before, during, and after the War of the Pacific. It is precisely during this period that high-ranking members of the Peruvian Catholic Church took on a leading role by assuming various government positions.

Keywords: Peruvian-Holy See diplomatic relations, history of the Church in Peru, Catholic Church, War of the Pacific (1879-1883).

\section{Resumo}

A história política é uma disciplina com uma longa história no Peru, mas há uma lacuna historiográfica notável nas relações diplomáticas que o Peru manteve com a Santa Sé (Roma) na segunda metade do século XIX. Por isso, serão examinadas as fontes históricas do Arquivo do Ministério das Relações Exteriores e da Biblioteca Nacional do Peru. O objetivo deste trabalho é acompanhar a forma como a política externa do Estado peruano foi proposta para alcançar os diversos objetivos nacionais da Santa Sé. Isso inclui reconstruir os vários momentos de coordenação entre o Ministério das Relações Exteriores com a legação peruana em Roma, nos quais a família Mesones desempenha um papel central: Luis Mesones e Manuel A. Mesones (1859-1887), ou seja, antes e depois da Guerra do Pacífico. Precisamente, é neste período que a alta hierarquia da Igreja Católica peruana torna-se uma protagonista importante ao assumir vários cargos no Estado.

Palavras-chave: Relações diplomáticas Peru-Santa Sé, História da Igreja no Peru, Igreja Católica, Guerra do Pacífico (1879-1883). 


\section{Introducción. Las relaciones diplomáticas entre el Perú y la Santa Sede para comprender la historia de la Iglesia en el Perú}

El artículo realiza un estudio descriptivo de las relaciones diplomáticas entre el Perú y la Santa Sede antes, durante y después de la guerra con Chile. Esto se desarrolla a través del seguimiento de la relación entre el Estado y la Iglesia, expresada en la actuación de entidades como el Ministerio de Relaciones Exteriores, la legación peruana en la Santa Sede, la alta jerarquía eclesiástica peruana y los delegados apostólicos (proceso de romanización). En otras palabras, la dimensión diplomática se apreciará en la interacción de estos actores en la concreción de los objetivos del Perú, como la designación de obispos, la acción de la legación peruana en la Santa Sede, mostrando su capacidad, influencia y maniobra para lograrlo. Este estudio de caso se basa en el importante papel que cumplió la familia Mesones durante un dilatado período (1860-1887), en el que activó una serie de relaciones personales, políticas y sociales.

La historia de la Iglesia en la segunda mitad del siglo XIX es todavía un tema pendiente para la historiografía peruana, a pesar de haber sido examinada en parte por Klaiber (1996), García Jordán (1998), Armas (2007) y Valdez (2004). Algunos ejes que podrían examinarse son la participación de la alta jerarquía eclesiástica en las redes de poder, su relación con los presidentes peruanos, las relaciones diplomáticas entre el Perú y la Santa Sede, el papel de los diplomáticos peruanos en Roma (Bartolomé Herrera, Pedro Gálvez, la familia Mesones, Juan Mariano de Goyeneche), los debates en la prensa limeña sobre el rol de la Iglesia, el papel de las órdenes religiosas en diversas regiones del país, y la participación de los sacerdotes en medio de la ocupación militar chilena (1882-1883), entre otros.

En esa línea, la guerra con Chile (1879-1883) se inscribió dentro de esas relaciones diplomáticas como un hito histórico que divide la historia de la Iglesia en el Perú. Es importante resaltar que, a pesar de su importancia, no contamos con trabajos que muestren el detalle de los conflictos entre el Estado y la Iglesia en esa coyuntura. El artículo ha identificado algunas señales que necesitan profundizarse: la participación de obispos en cargos en el Estado durante la guerra o las tensiones que indica Magdalena Chocano entre los liberales y el apoyo de la Iglesia al gobierno de Piérola en el Consejo de Estado (1880). Por esta razón, aún queda pendiente examinar con mayor detenimiento las fuentes eclesiásticas que aguardan ser recuperadas por investigadores para su discusión en la comunidad académica y la generación de nuevos estudios. Esta información se encuentra en el Archivo Arzobispal de Lima, el Ministerio de Justicia y Culto, así como en documentación recogida por la prensa de la época. 
Por otro lado, ¿Por qué era importante la misión de Manuel Mesones en el contexto de la guerra? Definitivamente, porque estaba a su cargo el nombramiento de nuevos obispos y también hacía frente a la mutilación territorial que no solo significaba la pérdida de Tarapacá, Tacna y Arica sino también el apartamiento de la feligresía peruana, convertida ahora en chilena por el cautiverio al que fueron sometidas. Asimismo, lograr el reconocimiento internacional implicaba no solo la reapertura de legaciones diplomáticas sino también el reconocimiento de facultades como Estados para reiniciar negociaciones y formulación de tratados entre los gobiernos de ambos países. Esa dinámica diplomática fue un elemento gravitante en el desarrollo de la guerra, toda adhesión que pudiese conseguir el gobierno peruano se sumaba a un frente internacional que respaldase su lucha contra Chile y en los años de posguerra.

Justamente, tras la firma del tratado de Ancón (octubre de 1883), que sellaría la suerte del Perú en la guerra, se obligó al gobierno de Miguel Iglesias a emprender la reanudación de las relaciones diplomáticas con los diversos países de América y Europa, aunque todavía se apreciaba la resistencia para que se le reconociese como legítimo gobierno por la guerra civil que sostenía con el general Cáceres en el centro del país. En este nuevo esquema, retomar las relaciones con la Santa Sede fue una pieza clave en Europa y por ello se produjo una disputa entre los agentes diplomáticos que enviaron ambos caudillos: Mesones (Cáceres) y García y García (Iglesias). Cada uno apelaría a diversos recursos para conseguir los objetivos planteados para ese momento: el nombramiento de nuevos obispos y velar por la situación futura de la feligresía en los territorios perdidos.

\section{Reconstrucción de la dinámica diplomática entre el Perú y la Santa Sede durante la segunda mitad del siglo XIX}

Para organizar la historia de la acción de la Iglesia en el Perú, García Jordán (1998, p. 352) propuso una periodización que también nos permite apreciar la evolución de las relaciones internacionales de nuestro país con la Santa Sede:

- 1821-1844: Construcción de la Iglesia nacional luego de la Independencia.

- 1845-1879: Era del guano, ofensiva liberal y respuesta de la Iglesia.

- 1880-1919: Estado moderno, secularización y radicalización de los sectores católicos.

En este caso, luego de revisar las fuentes históricas del Ministerio de Relaciones Exteriores y bibliografía especializada, se elaboró una relación de los diplomáticos del Perú enviados ante la Santa Sede en la segunda mitad del siglo XIX, en la que muestran el papel de dos personajes claves en Europa y la legación peruana en la Santa Sede antes y después de la guerra con Chile: Luis Mesones (1857-1865) y su hijo Manuel M. Mesones (1879-1887) 
Cuadro 1. Misiones diplomáticas del Perú ante la Santa Sede (1850-1887)

\begin{tabular}{cccc}
\hline N. ${ }^{\circ}$ & Diplomático & Año & Cargo \\
\hline 1 & Bartolomé Herrera & $1852-1853$ & Enviado extraordinario y ministro plenipotenciario \\
2 & Luis Mesones & $1859-1861$, & Enviado extraordinario y ministro plenipotenciario \\
& & 1865 & \\
3 & Pedro Gálvez & $1873-1878$ & Enviado extraordinario y ministro plenipotenciario \\
4 & Juan Mariano Goyeneche & 1878 & Enviado extraordinario y ministro plenipotenciario \\
5 & Manuel Mesones & $1882-1883$ & Ministro residente \\
6 & Aurelio García y García & $1884-1885$ & Enviado extraordinario y ministro plenipotenciario \\
7 & Manuel Mesones & 1885 & Agente confidencial \\
8 & Manuel Mesones & $1886-1887$ & Ministro residente \\
9 & Juan Mariano Goyeneche & $1887-1888$ & Enviado extraordinario y ministro plenipotenciario \\
\hline
\end{tabular}

Fuente: Elaboración propia sobre la base de Valdez (2004: 60-61), Paz Soldán (1891: 297-298), Iannettone (2007: 59-60, 121-128, 241, 249. 265), Ministerio de Relaciones Exteriores (http:// portal.rree.gob.pe/Santasede/SitePages/bilateral.aspx), Memoria que el Ministerio de Relaciones Exteriores presenta al Congreso de la República (años 1878, 1885, 1888), Libros copiadores del Archivo Central de Ministerio de Relaciones Exteriores: CC 126, CC 158, CC 167. Sesión del Consejo de Ministros del 9 de octubre de 1878 (Revista Histórica tomo XXXII, 1979-1980. Pp. 44).

Lo que llama la atención en este cuadro es la recurrente participación de dos miembros de la familia Mesones (Luis Mesones y Manuel Mesones) en la gestión de la legación peruana en la Santa Sede. Uno en la década de 1860 y otro en la de 1880. Por ello, este estudio nos mostrará las razones de esta continuidad en el tiempo. Ahora bien, en el caso de la Santa Sede, debemos tener en cuenta que se iniciaba el proceso de romanización, mediante el cual se producía la centralización y unificación institucional entre las diversas Iglesias nacionales con la Curia romana, colocando como eje central al Papa. En ese sentido, León XIII (18781903) enfatizó este proceso al utilizar una figura política y diplomática de la Santa Sede en América y otros continentes: los nuncios y delegados apostólicos. Estos no solo mediarían como representantes entre los Estados sino también como miembros de la Iglesia en Roma ante los obispos y la feligresía (De Roux, Rodolfo, 2014, pp. 31-37).

Por esta razón, se ha elaborado una relación de los secretarios de Estado y de los nuncios apostólicos de la segunda mitad del siglo XIX, cuyos trabajos estuvieron vinculados al Perú. 
Cuadro 2. Secretarios de Estado de la Santa Sede 1852-1903

\begin{tabular}{ccc}
\hline N. & Secretario de Estado & Años \\
\hline 1 & Giacomo Antonelli & $1852-1876$ \\
2 & Giovanni Simeoni & $1876-1878$ \\
3 & Alessandro Franchi & 1878 \\
4 & Lorenzo Nina & $1878-1880$ \\
5 & Lodovico Jacobini & $1880-1887$ \\
6 & Mariano Rampolla del Tindaro & $1887-1903$ \\
\hline
\end{tabular}

Fuente: Elaboración propia sobre la base de Catholic-Hierarchy https://www.catholic-hierarchy. org/diocese/dxxpe.html

De acuerdo con la bibliografía revisada, no se dispone de estudios especializados sobre el papel de los nuncios apostólicos en el Perú para el siglo XIX y XX. Por ello, se elaboró un cuadro, donde se detalla el nombre, cargo y años de representación de los diplomáticos de la Santa Sede en nuestro país.

Cuadro 3. Nuncios apostólicos en el Perú (1869-1889)

\begin{tabular}{|c|c|c|c|}
\hline N. ${ }^{\circ}$ & Delegado apostólico & Años & Cargo \\
\hline 1 & Serafino Vannutelli & $1869-1875$ & $\begin{array}{l}\text { Arzobispo de Nicea. Delegado apostólico para el } \\
\text { Ecuador, Perú, Venezuela, El Salvador, Guatemala, } \\
\text { Costa Rica, Honduras, Nicaragua. }\end{array}$ \\
\hline 2 & Mario Mocenni & $1877-1882$ & $\begin{array}{l}\text { Arzobispo de Heliopolis. Delegado apostólico } \\
\text { en Ecuador, Perú, Bolivia, Chile, Venezuela, } \\
\text { Guatemala, Costa Rica, Honduras, Nicaragua. }\end{array}$ \\
\hline 3 & Cesare Sambucetti & $1882-1883$ & $\begin{array}{l}\text { Arzobispo de Corinto. Delegado apostólico en } \\
\text { Ecuador, Perú, Bolivia. }\end{array}$ \\
\hline 4 & Beniamino Cavicchioni & $1884-1889$ & $\begin{array}{l}\text { Arzobispo de Amida. Delegado apostólico en } \\
\text { Ecuador, Bolivia, Perú. }\end{array}$ \\
\hline
\end{tabular}

Fuente: Elaboración propia sobre la base de Catholic-Hierarchy https://www.catholic-hierarchy. org/diocese/dxxpe.html

\section{Luis Mesones (1857-1872): Su carrera diplomática en Europa ${ }^{1}$ y el debate en Lima de 1872}

Las primeras noticias que tenemos sobre Luis Mesones nos llevan a 1850 en las memorias de Manuel de Argumaniz, un importante comerciante vinculado con las casas comerciales Zaracóndegui y Candamo. Asimismo, había fundado un banco y realizaba viajes a Europa como parte de sus actividades comerciales, interrelacionándose con muchos diplomáticos peruanos y extranjeros en Europa. En sus memorias narró que en 1857 emprendió un viaje a Francia, llevando consigo

1. Es escasa la información que se dispone sobre la biografía y carrera diplomática de Luis Mesones. De acuerdo con Pedro Paz Soldán y Unanue, Luis Mesones tuvo los siguientes puestos diplomáticos en Europa: Francia (1858), Estados Pontificios (1859-1861), Gran Bretaña (1862), Italia (1863-1866) (Paz Soldán: 1891, 298-301). 
a uno de sus sobrinos para educarlo en Europa y que pueda conocer de cerca su profesión.

Sin embargo, este joven desobedecía todas sus indicaciones y se entregó a una vida nada austera (Armas \& Monsalve, pp. 32, 498, 504). Cansado de estos desplantes, Argumaniz decidió devolver a su sobrino a Lima. Sin embargo, el joven acudió al consulado peruano que estaba a cargo Luis Mesones, pidió apoyo alegando que ya era mayor de edad y provenía de una familia de buena fortuna. De esta forma, logró detener la orden de captura de la prefectura de policía de París (Armas \& Monsalve, pp. 505-507).

Luego, en 1859, Luis Mesones se hizo cargo de la legación peruana en la Santa Sede, esperaba afianzar los lazos (Klaiber, pp. 104-105; Valdez, p. 61) y concretar los objetivos pendientes de la misión de Bartolomé Herrera (1852) como el Concordato entre el Perú y la Santa Sede y el reconocimiento oficial de nuestro país como República independiente. Otros asuntos que Mesones tendría que examinar fueron el proyecto de Patronato y el envío de un delegado apostólico como representante diplomático de la Santa Sede en el Perú. El primer enviado en América Latina fue monseñor Serafino Vannutelli que llegó en 1871. Había nacido en Italia en 1834 y previamente a su llegada al Perú fue secretario de la nunciatura en Baviera. Tras su paso por nuestro país fue designado nuncio papal en Bélgica y Austria hasta ser nombrado cardenal por el Papa León XIII el 4 de marzo de 1887 (Iannettone, pp. 18-19, 24-34).

Sin embargo, Mesones fue retirado de la Santa Sede y trasladado hacia la legación peruana en Italia en 1862 (MRE, 1862). Posteriormente, reasumió su puesto en el Vaticano en 1865 (Iannettone, pp. 122-128), pero al sobrevenir la guerra del Perú con España en 1866, retornó a Lima, donde fue elegido parlamentario por Huancabamba en el Congreso Constituyente de 1867 (Tuesta, 2001, 209). Fue reemplazado en la Santa Sede por Pedro Gálvez, quien entre 1873 y 1875 gestionó el Patronato en el Perú como el privilegio por el cual el presidente de la República podía nombrar nuevos obispos (Iannettone, pp. 60-62; Vargas, 1939, p. 135).

Posteriormente, Mesones retornó a la función diplomática y fue ministro residente del Perú en Argentina entre 1870 y $1872^{2}$. En este último año, Mesones entabló una dura polémica con el delegado apostólico Vannutelli en diversas publicaciones limeñas en torno a su posición laica y sus opiniones sobre la Iglesia, detalles que fueron comunicados a la Secretaría de Estado del Vaticano (Iannettone, pp. 3646). Luego de esta polémica, Mesones debía considerar «que había llegado el momento de volver al redil y de adoptar la semblanza del hijo de la Iglesia y de

2. Ministerio de Relaciones Exteriores. https://cdn.www.gob.pe/uploads/document/file/364679/Representantes del Peru en Argentina.pdf Consultado el 27 de julio de 2020. 
su devoto servidor». Es decir, hizo un giro estratégico para preservar su carrera diplomática y la de su hijo Manuel (Iannettone, p. 50). Para 1877, llegó al Perú un nuevo delegado apostólico, monseñor Mario Mocenni.

Finalmente, Mesones suscribió en 1876 el convenio Mesones Guiroy sobre el juicio relacionado al guano con Thomson Bonar y fue miembro de la comisión de delegados fiscales en Europa hasta 1878 (Basadre, 1964, pp. 248, 250). El último registro que se ha identificado sobre Mesones es de febrero de 1877, cuando el gobierno de Prado propuso ratificarlo en el cargo presidente de la Comisión Fiscal en Inglaterra. No obstante, Mesones mantuvo su posición de no continuar en el puesto $^{3}$. Por otro lado, como agente fiscal, Mesones tuvo un incidente con Daniel Ruzo, uno de los principales diplomáticos del Perú en Inglaterra, a raíz de un hurto declarado en 1871 en uno de los cargamentos que se dirigía a Irlanda, siendo declarado responsable por Mesones, presidente de la Comisión Fiscal, y obligado a pagar una indemnización ${ }^{4}$. Ruzo pidió apoyo legal para apelar y obtener una suma a su favor ${ }^{5}$. Sin embargo, hasta 1880 no hubo respuesta porque la legación en Francia evaluaría el retiro de la demanda en los tribunales de Londres.

3. Sesiones del Consejo de Ministros del 10 y 13 de febrero de 1877. En: Revista Histórica tomo XXXII, 1979-1980, pp. 28-29.

4. Biblioteca Nacional del Perú (en adelante, BNP). Archivo Piérola. Sobre 5000000859. Carta de Daniel Ruzo a Nicolás de Piérola. Londres, 31 de marzo de 1880.

5. BNP. Archivo Piérola. Sobre 5000000859. Carta de Daniel Ruzo a Nicolás de Piérola. Londres, 15 de junio de 1880.

6. BNP. Archivo Piérola. Sobre 5000000857. Carta de Toribio Sanz a Nicolás de Piérola. París, 16 de junio de 1880 . 
Fotografía 1. Luis Mesones, jefe de la misión diplomática del Perú en la Santa Sede (1859-1861, 1865)

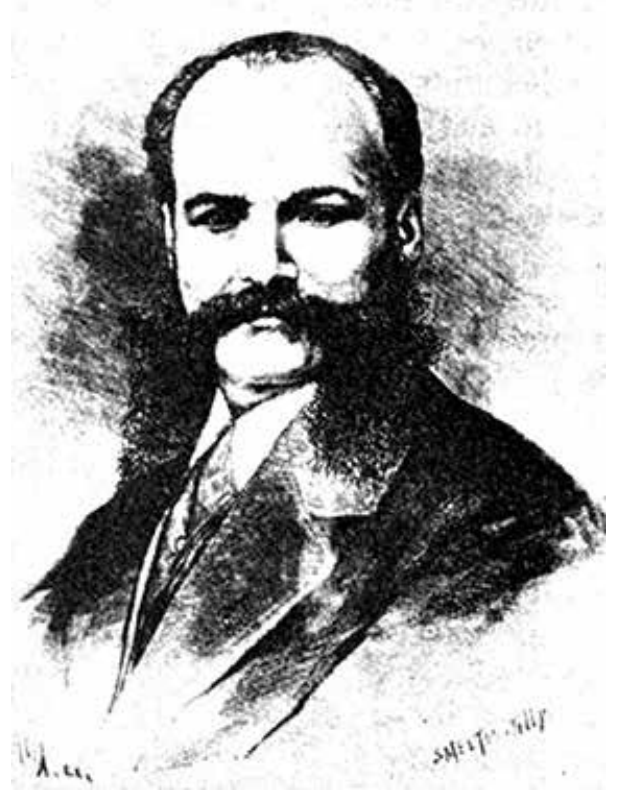

Fuente: Wikimedia Commons. https://commons.wikimedia.org/wiki/Main_Page

Fotografía 2. Serafino Vannutelli, delegado apostólico de la Santa Sede en el Perú (1869-1875)

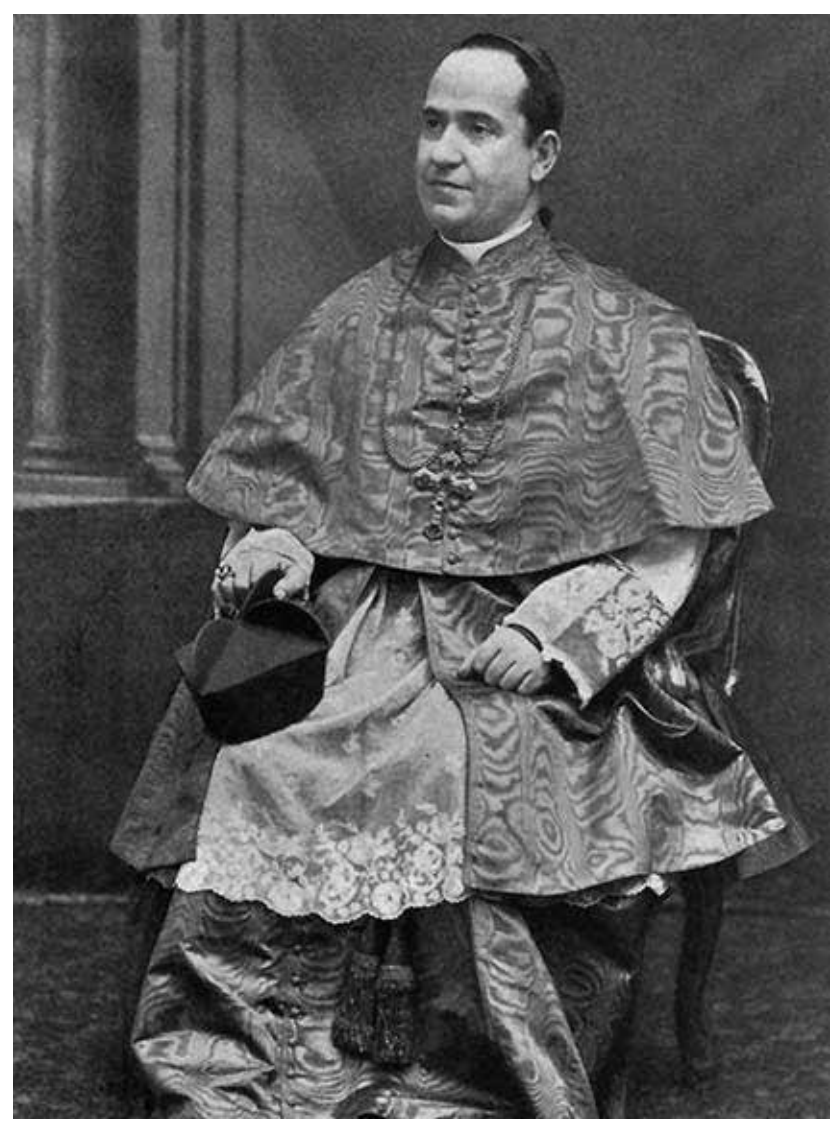

Fuente: Araldicavaticana. http://www.araldicavaticana.com/ 


\section{Manuel María Mesones: La diplomacia como un nuevo frente en la guerra y posguerra (1879-1887)}

\section{La misión de Mesones en Roma en 1879 y las relaciones con la Santa Sede entre 1880 y 1881}

La Guerra del Pacífico es uno de los hitos en la historia de la Iglesia y en las relaciones diplomáticas que estableció el Perú a nivel internacional. Sin embargo, las investigaciones sobre la Iglesia durante este período son escasas, debido a la dificultad en el acceso a nuevas fuentes de información que permitan renovar los estudios sobre la guerra ${ }^{7}$. Por otro lado, la dirección de la política exterior se vinculaba con la participación política y la cooperación cercana que existió principalmente entre la alta jerarquía de la Iglesia y los gobiernos anticivilistas. Es decir, no es casualidad que obispos se involucrarán en la conducción política en los regímenes de Piérola e Iglesias, porque se oponían a la proximidad de muchos civilistas con el liberalismo y la masonería, tal como sostiene Chocano (2010, p. 437). Veamos el siguiente detalle:

Cuadro 4. Obispos que aceptaron cargos dentro del Estado durante la Guerra del Pacífico y Reconstrucción Nacional (1879-1886)

\begin{tabular}{|c|c|c|c|c|}
\hline $\mathrm{N}^{\circ}$ & Obispo & Cargo & Gobierno & Cargo en el Estado \\
\hline 1 & $\begin{array}{l}\text { Monseñor Francisco } \\
\text { Orueta y Castrillón }\end{array}$ & $\begin{array}{l}\text { Arzobispo de } \\
\text { Lima }\end{array}$ & $\begin{array}{c}\text { Mariano } \\
\text { Ignacio Prado }\end{array}$ & $\begin{array}{l}\text { Presidente de la Junta Central de } \\
\text { Administradora de Donativos de } \\
\text { la Guerra con Chile (1879-1880) }\end{array}$ \\
\hline 2 & $\begin{array}{l}\text { Monseñor Francisco } \\
\text { Orueta y Castrillón }\end{array}$ & $\begin{array}{l}\text { Arzobispo de } \\
\text { Lima }\end{array}$ & $\begin{array}{l}\text { Nicolás } \\
\text { de Piérola }\end{array}$ & $\begin{array}{l}\text { Presidente del Consejo de Estado } \\
\text { (1880) }\end{array}$ \\
\hline 3 & $\begin{array}{l}\text { Monseñor Francisco } \\
\text { Solano del Risco }\end{array}$ & $\begin{array}{l}\text { Obispo de } \\
\text { Chachapoyas }\end{array}$ & $\begin{array}{l}\text { Miguel } \\
\text { Iglesias }\end{array}$ & $\begin{array}{l}\text { Presidente de la Asamblea del } \\
\text { Norte (1883, pero no asistió a las } \\
\text { sesiones). }\end{array}$ \\
\hline 4 & $\begin{array}{l}\text { Monseñor Pedro } \\
\text { José Tordoya }\end{array}$ & $\begin{array}{l}\text { Obispo de } \\
\text { Cusco }\end{array}$ & $\begin{array}{l}\text { Lizardo } \\
\text { Montero }\end{array}$ & $\begin{array}{l}\text { Delegado de la Delegación del } \\
\text { Supremo Gobierno en Lima. }\end{array}$ \\
\hline 5 & $\begin{array}{l}\text { Monseñor Manuel } \\
\text { Tovar y Chamorro }\end{array}$ & $\begin{array}{l}\text { Obispo Titular } \\
\text { de Marcópolis }\end{array}$ & $\begin{array}{l}\text { Miguel } \\
\text { Iglesias }\end{array}$ & Ministro de Justicia y Culto (1885) \\
\hline 6 & $\begin{array}{l}\text { Monseñor Manuel } \\
\text { Tovar y Chamorro }\end{array}$ & $\begin{array}{l}\text { Obispo Titular } \\
\text { de Marcópolis }\end{array}$ & $\begin{array}{l}\text { Consejo de } \\
\text { Ministros conjunto } \\
\text { Cáceres - Iglesias }\end{array}$ & $\begin{array}{c}\text { Diputado de la Asamblea } \\
\text { Constituyente (1884-1885) y } \\
\text { ministro de Justicia y Culto (1885- } \\
\text { 1886) }\end{array}$ \\
\hline
\end{tabular}

Fuente: Elaboración propia sobre la base de Abanto (2017, p. 128), Libro de actas del Consejo de Estado (Documento 2000022357), De la Puente Candamo, José \& De la Puente Brunke, José, (2016, pp.39-40), De la Puente Candamo, J. \& De la Puente Brunke, J. (2008, p. 718). Basadre (1964, p. 2671), Catholic-Hierarchy https://www.catholic-hierarchy.org/.

7. Este es el espíritu de trabajos como el de Oswaldo Holguín sobre las relaciones entre la jerarquía eclesiástica con la capellanía castrense chilena durante los años de ocupación (Holguín, 1972, p. 169) y José Carlos Martín, respecto a la labor de la orden jesuita en la campaña del sur y la defensa de Lima (Martín, 1973-1975, p. 511). En esa misma línea, son los estudios recientes de César Cordero (2020), en donde se examinan las cartas pastorales y oraciones fúnebres de los obispos peruanos durante la guerra. María Lucía Valle (2013) revisó fuentes parroquiales con el registro de matrimonios entre chilenos y peruanos durante 1881-1883 en la capital. 
Estos vínculos políticos de los jerarcas de la Iglesia influenciarán en las futuras gestiones diplomáticas de Manuel M. Mesones como nuevo actor en la política exterior, en cuyas manos se encontraba el destino de las relaciones con la Santa Sede durante la guerra con Chile y los años de posguerra.

Ahora bien, ¿quién fue Manuel Mesones y por qué fue clave durante la guerra del Pacífico? No hay mucha información biográfica al respecto porque no ha sido un personaje muy examinado por la historiografía ${ }^{8}$. Iannettone señaló que Manuel Mesones fue un hijo concebido fuera del matrimonio de Luis Mesones y que en 1868 se enroló en los zuavos pontificios. Años después, gracias a los contactos y redes de clientelaje establecidas por su padre, buscaría un puesto en cualquier legación peruana en Europa para después casarse con Luisa Jacobini, quien pertenecía a una de las más importantes familias vinculadas al Vaticano y al secretario de Estado del Sumo Pontífice, Ludovico Jacobini (Iannettone, pp. 65-67).

Desatada la guerra con Chile en 1879, el Ministerio de Relaciones Exteriores dispuso la apertura de diversas legaciones peruanas en América y Europa como parte de un nuevo frente de guerra. ¿Qué pasó con el joven Mesones? Es posible que sus influencias hayan determinado el nombramiento de Mesones en las legaciones del Perú en Italia y la Santa Sede, sin tener necesariamente la experiencia diplomática suficiente. Y esa inexperiencia le hizo cometer un grave error que le costaría el puesto de secretario en la legación en Italia: solicitó la mediación de ese país en la guerra sin la previa autorización de la Cancillería de Lima.

¿Cuáles fueron los antecedentes de este incidente? El ministro del Perú en Italia, Luciano Benjamín Cisneros, solicitó en febrero de 1879 el reemplazo de su secretario (capitán de navío Toribio Raygada), quien partía al Perú por motivos de salud, por su recomendado Manuel Mesones para que se presentase de inmediato en Roma ${ }^{9}$. Sin embargo, el canciller Manuel Irigoyen desaprobó en junio la acción unilateral del secretario Mesones por haber solicitado al Gobierno de Italia interponer su mediación en la guerra del Pacífico. Y no estuvo solo, esta decisión fue confirmada por el presidente Prado en una carta personal al vicepresidente La Puerta: «Es una desvergüenza lo que ha hecho ese Mesones, titulado secretario de nuestra Legación en Roma, al solicitar los buenos oficios del Gobierno de Italia, sin estar autorizado para ello, y debe por consiguiente destituírsele inmediatamente» ${ }^{10}$. Por esta razón, el canciller Irigoyen le consultó a Cisneros si tuvo su autorización para

8. Cabe precisar que se ha tenido que desambiguar a Manuel María Mesones (materia de este estudio: hijo de Luis Mesones y jefe de la legación peruana en la Santa Sede) con otros personajes homónimos como Manuel Antonio Mesones Muro (1862-1930) y Manuel Antonio Mesones Piedra (1888-1948)

9. Archivo del Ministerio de Relaciones Exteriores (en adelante, ACMRE). CC 133. Oficio del Ministerio de Relaciones Exteriores al Ministerio de Guerra y Marina. Lima, 25 de abril de 1879.

10. Carta de Mariano Ignacio Prado a Luis La Puerta. Arica, 21 de junio de 1879. En: Revista Histórica tomo XXXII (1979-1980, p. 245). 
hacer tal gestión, le pedía efectuar las indagaciones para resolver este incidente diplomático y criticó la actitud de Mesones por esta irresponsabilidad ${ }^{11}$.

En agosto, Giovanni Viviani, encargado de negocios de Italia en el Perú, se entrevistó con Irigoyen para saber cuál era el carácter diplomático de Mesones en Roma, el porqué Cisneros no conducía la legación peruana desde febrero de 1879 y para pedirle explicaciones por el incidente de la mediación diplomática. A esto, Irigoyen contestó que Mesones solo era secretario interino y consideraba este suceso como grave porque ponía en entredicho el nombre del Perú. Por ello, dispuso la cancelación inmediata del nombramiento de Mesones y le pedía a Cisneros ejecutarla lo más pronto posible ${ }^{12}$.

Fotografía 3. Ludovico Jacobini, secretario de Estado de la Santa Sede. (1880-1887)

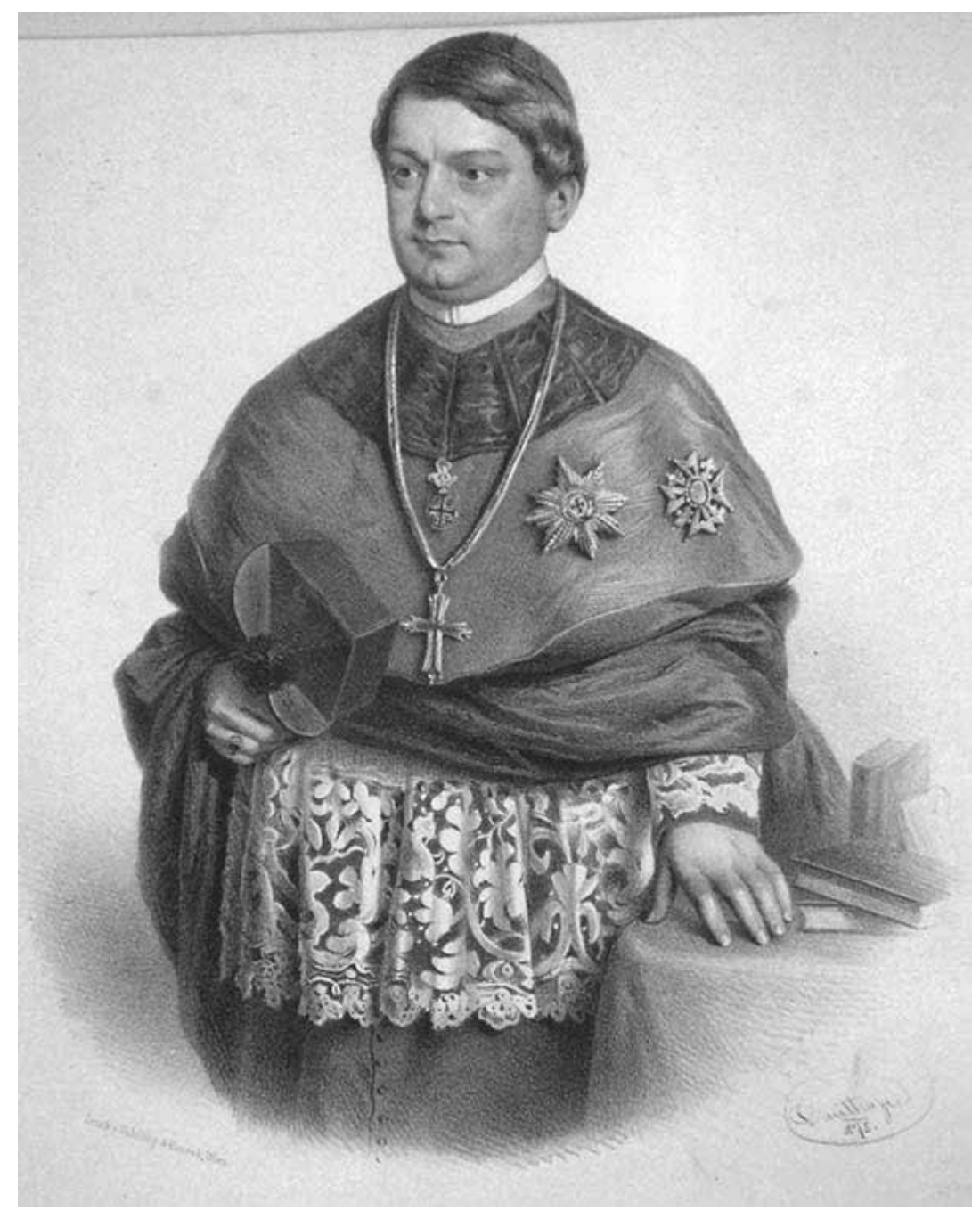

Fuente: Wikimedia Commons. https://commons.wikimedia.org/wiki/Main Page

11. ACMRE. CC 139. Oficio del Ministerio de Relaciones Exteriores a la legación del Perú en Italia. Lima, 11 de junio de 1879.

12. ACMRE. CC 126. Oficio del Ministerio de Relaciones Exteriores a la legación del Perú en Italia. Lima, 27 de agosto de 1879. 
Para ese momento, Juan Mariano Goyeneche había sido nombrado ministro plenipotenciario del Perú ante la Santa Sede el 9 de octubre de 1878, a raíz de la muerte, ese año, del antiguo agente diplomático Pedro Gálvez ${ }^{13}$. Posteriormente, Goyeneche acogió como secretario a Manuel Mesones el 27 de agosto de 1879, tras su incidente en Roma. Esta vez, el delegado apostólico fue monseñor Mocenni, quien interrogó por pedido de monseñor Nina, secretario de Estado de su Santidad, al canciller Irigoyen sobre cuál era la situación legal de Mesones. Al igual que Cisneros, Irigoyen le pidió a Goyeneche un informe para determinar si Mesones continuaría en su puesto o si desvanecía todas las acusaciones en su contra ${ }^{14}$.

Por otro lado, entre 1880 y 1881, Piérola apostó por una comunicación directa de Estado a Estado, por lo que no restableció la acción de la misión diplomática en la Santa Sede, encargada anteriormente a Goyeneche y Mesones. Sin embargo, las relaciones del Estado con la Iglesia la convirtieron en un actor fundamental en lo económico y lo político. Como agente económico respondió al llamado del gobierno de Piérola con el préstamo de objetos preciosos de varias iglesias como garantía por la suma de S/. 15000 000 soles y entregadas al Banco de Londres, México y Sudamérica (Camprubí, 1957, p. 405). Asimismo, Fernando Armas precisó que otro préstamo de la Iglesia ascendió 134,529.14 soles y subsistió hasta 1881 (Armas, 2001, pp. 83, 88, 93).

En lo político, la Iglesia tuvo un papel gravitante en el Consejo de Estado, una nueva entidad creada por Piérola que se instaló en enero de 1880 (Chaupis, 2012, 102), y donde el arzobispo de Lima ejerció la presidencia, encargándose de dirigir las sesiones y establecer la agenda en esta alta instancia consultiva. El acercamiento de la Iglesia se debió a la conjunción de intereses entre Piérola y el arzobispo de Lima frente al civilismo (liberalismo y masonería), mostrando posiciones ultramontanas (Chocano 2010, p. 437), vinculadas a la relación entre el Estado y la Iglesia. Los miembros del Consejo de Estado fueron ${ }^{15}$ :

- Presidencia: Arzobispo de Lima Francisco Orueta y Castrillón.

- Miembros institucionales: Antonio Arenas (Presidente del Congreso de Juristas), Juan Antonio Ribeyro (Presidente de la Corte Suprema de Justicia y rector de la Universidad de Lima).

- Consejeros titulares: Manuel F. Benavides, Manuel Lecca, general Pedro Diez Canseco, capitán de navío José Elcorrobarrrutia, José Jorge Loayza y Pedro A. del Solar (Secretario), Melchor García, José María La Torre Bueno, Manuel Santos Pasapera y Octavio Tudela.

13. Sesión del Consejo de Ministros del 9 de octubre de 1878. En: Revista Histórica tomo XXXII, 19791980, p. 44.

14. ACMRE. CC 126. Oficio reservado del Ministerio de Relaciones Exteriores a la legación del Perú en la Santa Sede. Lima, 17 de setiembre de 1879.

15. BNP. Libro de actas del Consejo de Estado. Documento 2000022357. Sesión ordinaria. Lima, 15 de enero de 1880. 
¿Qué aspectos específicos tuvo a cargo Orueta y Castrillón respecto al curso de la guerra en el Consejo de Estado? Entre junio y julio de 1880 se aprobaron los protocolos sobre la Confederación Perú Boliviana por parte de la Comisión Diplomática ${ }^{16}$ y el arzobispo de Lima señaló que el Consejo deliberaría «[...] conforme a las exigencias del patriotismo, a los intereses de la alianza y al triunfo de las armas nacionales» ${ }^{17}$. El pacto de Confederación quedaba expedito para su aprobación en un plebiscito nacional para su ratificación ${ }^{18}$.

Fotografía 4. Arzobispo de Lima Francisco Orueta y Castrillón

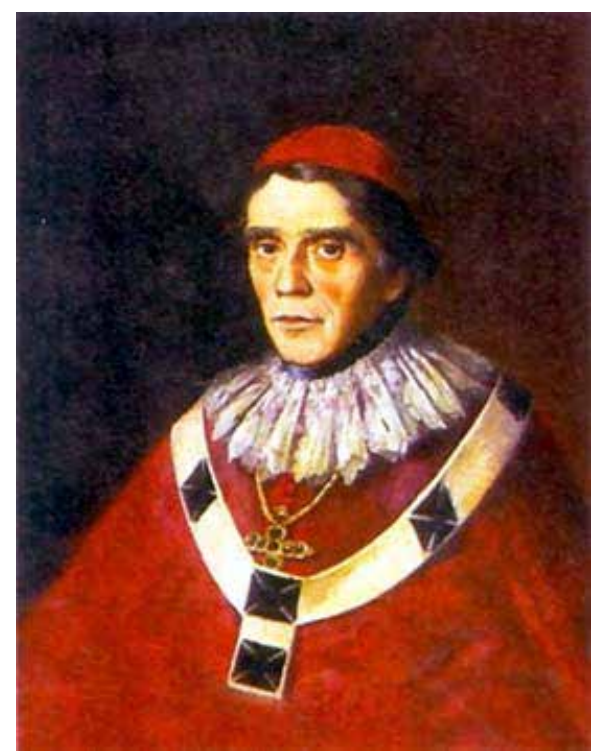

Fuente: Wikimedia Commons. https://commons.wikimedia.org/wiki/Main_Page

¿Qué tema vincularía la reactivación de las relaciones entre el Perú y la Santa Sede, sin necesidad de la mediación de una legación diplomática? Sin duda fueron la adopción del Patronato y el nombramiento de obispos por parte del Consejo de Estado y Piérola. La intervención del arzobispo Orueta y Castrillón también buscaba la renovación y nombramiento de nuevos obispos, ya que las últimas designaciones se realizaron en la década de 1870. En ese sentido, el Consejo de Estado tuvo la facultad de proponer a los obispos para la aprobación de Piérola, en conformidad con la habilitación del Patronato del Perú ante la Santa Sede. Roma había aprobado esta gestión bilateral iniciada por el diplomático Pedro Gálvez en 1874 y confirmada por el cardenal Nina, secretario de Estado del Vaticano, el 13 de abril de 1880 (Vargas Ugarte, 135; Rubio, 126-127; Chaupis, 82). Este documento se mantuvo subsistente hasta 1980 (Ministerio de Justicia y Derechos Humanos, 2016).

16. BNP. Libro de actas del Consejo de Estado. Documento 2000022357. Sesión ordinaria. Lima, 16 de junio de 1880

17. BNP. Libro de actas del Consejo de Estado. Documento 2000022357. Sesión ordinaria. Lima, 16 de junio de 1880.

18. BNP. Libro de actas del Consejo de Estado. Documento 2000022357. Sesión ordinaria. Lima, 8 de julio de 1880 . 
¿Qué obispos nombró el Consejo de Estado y comunicó a la Santa Sede? En mayo se propuso una terna para nombrar a un nuevo obispo en Cusco y reemplazar a monseñor Pedro José Tordoya. Sin embargo, la terna fue observada por la inclusión de monseñor Manuel A. Bandini ${ }^{19} \mathrm{y}$ fue nombrado en su lugar Gregorio Valenza $^{20}$. En junio, fray Juan Esfévanes y Seminario fue elegido como obispo de Puno $^{21}$, siendo comunicado al mes siguiente a la Santa Sede ${ }^{22}$. En agosto se aprobó el nombramiento de monseñor Juan Ambrosio Huertas como nuevo obispo de Arequipa ${ }^{23}$ y en noviembre se remitieron las bulas a la Santa Sede ${ }^{24}$.

\section{Manuel Mesones y las relaciones en la Santa Sede durante la ocupación chilena (1881-1883)}

En 1881, tras la caída de Lima en manos del ejército chileno, el Perú quedó con su Estado completamente desarticulado y dos caudillos disputándose el poder: Francisco García Calderón y Nicolás de Piérola. Cada uno recreó a su manera lo que quedaba del Estado: ambos convocaron gabinetes ministeriales, agentes diplomáticos en el extranjero, Congresos (Asamblea de Ayacucho y Congreso de Chorrillos) y órganos de prensa (El Orden contra periódicos regionales pierolistas). Tras la intervención decisiva de los Estados Unidos en favor de García Calderón, terminó con el desconocimiento a la autoridad de Piérola por parte de los principales jefes militares del país (Montero en el norte y futuro vicepresidente, Cáceres en el centro y De la Torre en el sur) (Abanto, 2012, pp. 91-93).

Sin embargo, el presidente García Calderón fue desterrado y en su lugar se conformó en Lima una Delegación del Supremo Gobierno que transmitía y coordinaba con las jefaturas político militares del centro y del sur, y también realizó funciones como agencia confidencial de las negociaciones diplomáticas que tenían como meta el reconocimiento internacional del gobierno de Lizardo Montero, sucesor de García Calderón (Abanto, 2017b, pp. 181-196). Esta Delegación funcionó entre 1881 y 1883 y estuvo conformada inicialmente por Manuel Candamo y Carlos

19. BNP. Libro de actas del Consejo de Estado. Documento 2000022357. Sesiones ordinarias. Lima, 8 y 29 de abril de 1880 .

20. BNP. Libro de actas del Consejo de Estado. Documento 2000022357. Sesiones ordinarias. Lima, 7 y 13 de mayo de 1880 .

21. BNP. Libro de actas del Consejo de Estado. Documento 2000022357. Sesión ordinaria. Lima, 3 de junio de 1880.

22. BNP. Libro de actas del Consejo de Estado. Documento 2000022357. Sesión del Consejo de Estado. Lima, 8 de julio de 1880 .

23. BNP. Libro de actas del Consejo de Estado. Documento 2000022357. Sesión del Consejo de Estado. Lima, 18 de noviembre de 1880.

24. BNP. Libro de actas del Consejo de Estado. Documento 2000022357. Sesión del Consejo de Estado. Lima, 2 de diciembre de 1880. 
Elías. Cuando ambos fueron detenidos y llevados como prisioneros a Chile (agosto de 1882), su lugar fue tomado por Alejandro Arenas, quien tuvo que escapar de Lima y entregó el mando al obispo de Cusco, Pedro José Tordoya.

Para 1883, el obispo Tordoya pudo evitar el acoso de las fuerzas chilenas por su investidura eclesiástica (De la Puente Candamo, José \& De la Puente Brunke, José, pp. 39-40). La Delegación pertenecía al círculo civilista y en esas relaciones estuvo el obispo Tordoya, por lo que los políticos del pierolismo criticaban su gestión como gestor de conspiraciones entre 1882 y 1883 . Uno de ellos fue Aurelio García y García ${ }^{25}$ en Londres y Juan Martín Echenique ${ }^{26}$ en Lima. Sin embargo, la participación política de Tordoya no era nueva, en 1867 había sido presidente del Consejo de Ministros, en medio de un contexto convulsionado, posterior al Combate de 2 de mayo en 1866. Por ello, llama la atención la aceptación del cargo de Montoya en plena ocupación chilena, justo cuando ningún político hubiese aceptado ser designado como titular de la Delegación. ¿Se opuso Tordoya al arzobispo de Lima? ¿Su cargo eclesiástico le brindaba cierta protección frente a las represalias e incidentes con las autoridades chilenas?

¿Qué temas se planteó la nunciatura apostólica en materia de relaciones entre el Perú y la Santa Sede en medio de la anarquía política? Para el primer semestre de 1882, la disputa por el poder tuvo como protagonistas a Lizardo Montero y Miguel Iglesias. El punto principal del conflicto entre ambos presidentes fue el reconocimiento internacional de otros países como una forma de legitimación, y el gobierno Montero se acercó a la Santa Sede para que así lo hiciera. No obstante, el delegado apostólico monseñor Mocenni nunca lo hizo efectivo, cuando Montero asumía el gobierno en Cajamarca ${ }^{27}$. No paso mucho tiempo para que Mocenni dejara el Perú y partiera a Brasil a representar a la Santa Sede en ese país, no sin antes reunirse con la Delegación de Lima, conformada por Carlos Elías y Manuel Candamo.

25. BNP. Archivo Piérola. Sobre 5000000859. Carta de Aurelio García y García a Nicolás de Piérola. Londres, 28 de agosto de 1883.

26. BNP. Archivo Piérola. Sobre 5000000831. Carta de Juan Martín Echenique a Nicolás de Piérola. Lima, 27 de diciembre de 1882.

27. Oficio de la Delegación del Supremo Gobierno al Ministerio de Relaciones Exteriores. № 35. Lima, 8 de marzo de 1882. En. El Estado en la sombra. P. 326. 
Fotografía 5. Monseñor Pedro José Tordoya

Obispo de Cusco y encargado de la Delegación del Supremo Gobierno en 1883.

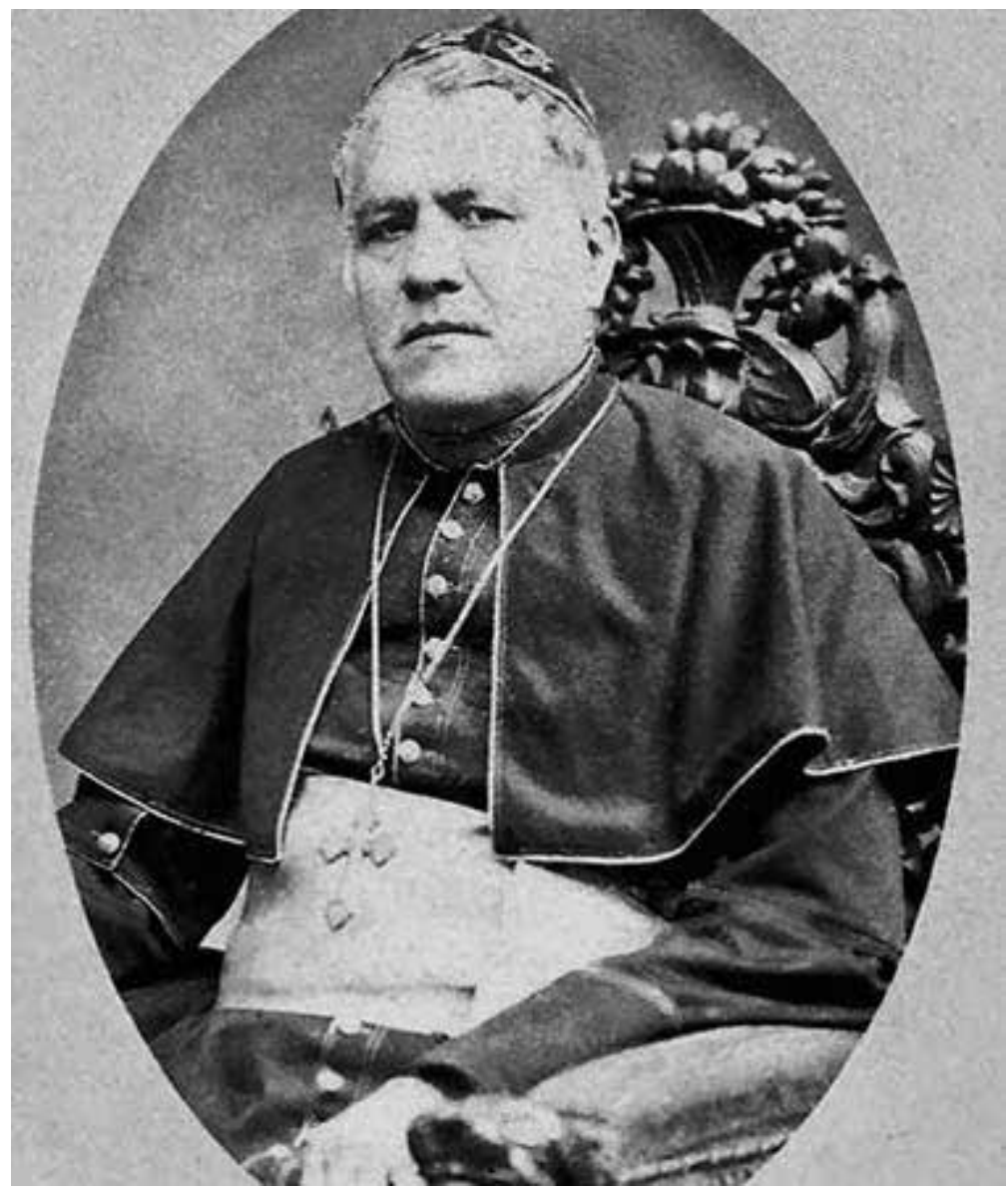

Fuente: Colección privada (Gálvez, J. \& García, E. P. 132.).

En esa entrevista, les pidió evaluar cubrir las vacantes de los obispados de Puno, Cusco y Trujillo; de lo contrario lo haría directamente el Santo Padre. A esto se sumó la repentina muerte del obispo de Ayacucho Juan José Polo en noviembre de 1882, en medio de un levantamiento indígena en Huanta (Guzmán, 1990, pp. 222-223) y que Ricardo Palma en el periódico El Canal de Panamá responsabilizó al subprefecto de esa provincia por provocar la sublevación e incitar a sus tropas a atacar la comitiva del obispo, lo que finalmente acabó con su vida ${ }^{28}$.

28. Carta de Ricardo Palma al director de El Canal de Panamá. Lima, 22 de noviembre de 1882. En: Guice, Norman $(1984,236)$. 
Fotografías 6 y 7. Mario Mocenni (1877-1882) y Beniamino Cavicchioni (1884-1889)

Delegados apostólicos de la Santa Sede en el Perú.
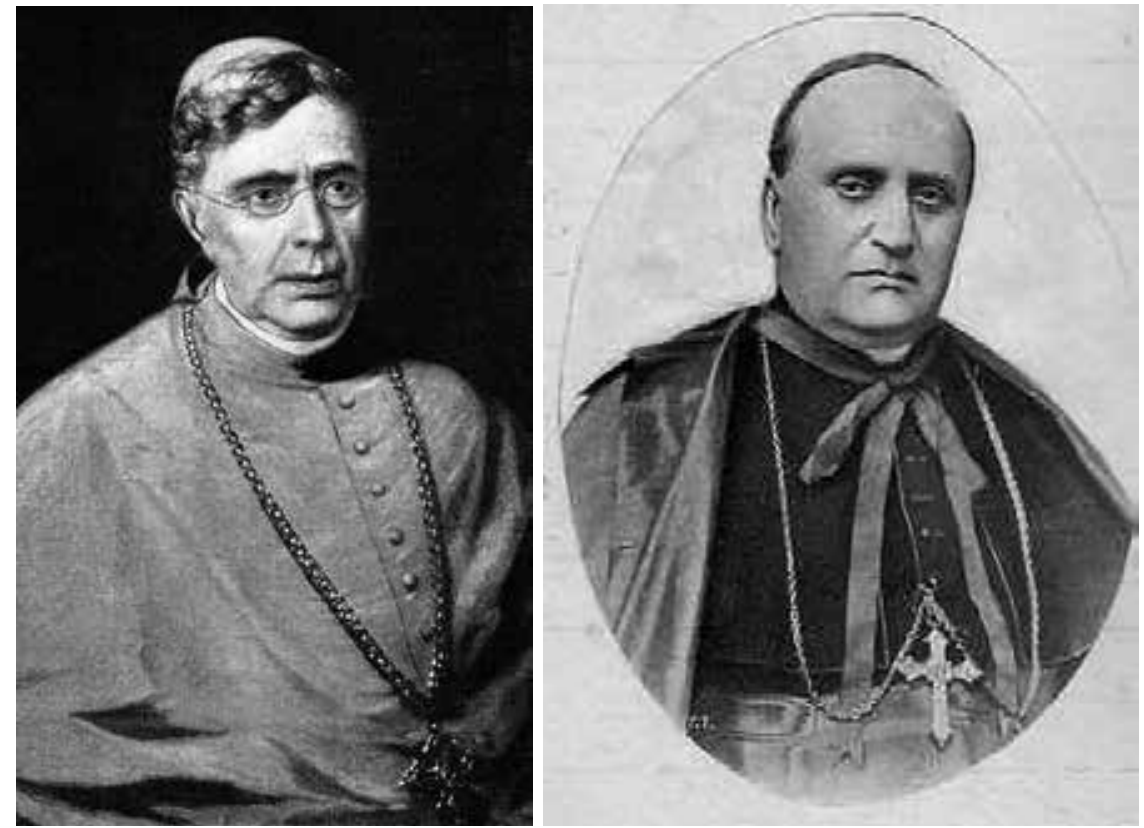

Fuente: Araldicavaticana. http://www.araldicavaticana.com/

Como podemos apreciar, el pedido de Mocenni era imposible cumplir debido a la situación que atravesaba el Perú. No obstante, se enviaría una terna con los candidatos al nuevo Congreso ${ }^{29}$. Meses después, monseñor César Sambucetti se presentó como nuevo delegado apostólico de la Santa Sede en el Perú para reiniciar relaciones diplomáticas ${ }^{30}$. Finalmente, en setiembre de 1883, es decir, más de un año después, el gobierno de Montero en Arequipa propuso una terna para el nombramiento de los nuevos obispos del Perú y presentarlos para la aprobación de la Santa Sede: para Puno a José María Carpenter (Cura de la Parroquia del Sagrario de Arequipa), Trujillo a Manuel Medina (Maestrecuela del Coro de la Arquidiócesis de Lima), Juan Manuel Rodríguez (Magistral del Cabildo de Ayacucho) y para Cusco a Julián Cáceres (Tesorero del Cabildo Eclesiástico de la Diócesis de Arequipa $)^{31}$.

Mientras tanto, ¿qué había sucedido con Manuel Mesones en Roma y cómo afectaba la crisis política a su reinstalación en la legación del Perú en la Santa Sede? En noviembre de 1882, Lizardo Montero nombró a Manuel Mesones como

29. ACMRE. Caja 282, file 17. Agentes confidenciales. 1882. Oficio de Delegación del Supremo Gobierno al Ministerio de Relaciones Exteriores. № 59. Lima, 23 de marzo de 1882.

30. ACMRE. CC 156. Oficio del Ministerio de Relaciones Exteriores a monseñor César Sambucetti delegado apostólico de la Santa Sede en el Perú. No 1 . Arequipa, 10 de enero de 1883.

31. Sesión de Consejo de Ministros del gobierno de Lizardo Montero. Arequipa, 8 de setiembre de 1883. En: Revista Histórica, tomo XXXII, 1979-1980, p. 142. 
jefe de la legación del Perú en la Santa Sede y enviaron sus cartas credenciales ${ }^{32}$. En una de las circulares dirigida a todas las misiones diplomáticas peruanas en el extranjero, incluyendo a la Santa Sede, el canciller Mariano Nicolás Valcárcel informó el cambio de ruta (la ruta Arica-La Paz o vía Buenos Aires-La Paz) para el envío de comunicaciones hacia Arequipa, utilizando alguna de las legaciones extranjeras como cubierta ${ }^{33}$.

En marzo de 1883, Mesones explicaba que tuvo un incidente en la Santa Sede porque al presentar sus cartas credenciales estuvieron dirigidas a la Secretaría de Estado del Vaticano y no al Sumo Pontífice. Sin embargo, este detalle fue resuelto y Mesones presentaría pronto estos documentos para su reconocimiento diplomático $^{34}$. La respuesta que obtuvo del secretario de Estado del Vaticano, Ludovico Jacobini, fue la siguiente:

Su Santidad se ha enterado con viva satisfacción que el señor Lizardo Montero, vicepresidente del Perú queriendo testimoniar los sentimientos de devoción del pueblo peruano hacia el Jefe Supremo de la Iglesia y estrechar cada vez más las amistosas relaciones existentes entre los dos poderes se ha determinado a restablecer un representante de la República ante la Santa Sede y que con tal fin haya conferido a V.S. el oficio de encargado de negocios ante la Santa Sede. (Iannettone, p. 71)

El 22 de abril, Mesones presentó sus cartas credenciales al Santo Padre y este le manifestó «su decidido interés que toma por la suerte de nuestra desventurada patria». ${ }^{35}$ Por ello, el canciller Valcárcel le pidió estrechar los vínculos del Perú con la Santa Sede y Mesones confirmó que este reconocimiento fue comunicado al cuerpo diplomático residente en Roma, lo que podría influir en una futura mediación de paz de los gobiernos europeos ${ }^{36}$. Sin embargo, estos deseos de Mesones se estrellaron contra la lucha por el poder entre Iglesias y Montero, porque desde Lima se envió un telegrama a Roma dirigido al secretario de Estado, monseñor Mocenni, pidiéndole que «no acepte la Santa Sede las presentaciones del señor Montero» (Iannettone, p. 72), es decir, que no se reconozca el carácter diplomático de Mesones.

32. ACMRE. CC 158.Oficio del Ministerio de Relaciones Exteriores a Manuel Mesones, encargado de negocios del Perú en la Santa Sede. Arequipa 7 de noviembre de 1882.

33. ACMRE. CC 158. Circular del Ministerio de Relaciones Exteriores a las legaciones del Perú en Italia, Francia e Inglaterra, España, Alemania y Santa Sede. Arequipa, 14 de noviembre de 1882.

34. ACMRE. CC 158. Oficio del Ministerio de Relaciones Exteriores a la legación del Perú en la Santa Sede. № 2. Arequipa, 2 de agosto de 1883.

35. ACMRE. CC 158. Oficio del Ministerio de Relaciones Exteriores a la legación del Perú en la Santa Sede. No 4 . Arequipa, 8 de junio de 1883.

36. ACMRE. CC 158. Oficio del Ministerio de Relaciones Exteriores a la legación del Perú en la Santa Sede. No 1 . Arequipa, 20 de julio de 1883. 
$\mathrm{Al}$ acercarse el final del gobierno de Montero, ocurrieron dos incidentes con la Iglesia por temas económicos. El primero ocurrió en julio de 1883, debido a que el Congreso en Arequipa discutió la intervención de las rentas del culto a la Virgen de Quilca, que habían sido otorgadas por la Santa Sede. Sin embargo, todo quedó paralizado hasta confirmar esta información en los archivos gubernamentales de Arequipa $^{37}$. Por otro lado, en agosto de 1883, el ministro de Gobierno Federico Herrera fue comisionado a Puno para adoptar medidas en materia de gobierno y hacienda ${ }^{38}$. A su regreso, después de casi un mes de trabajo, ${ }^{39}$ informó que en las sacristías de Chucuito había un excedente de plata labrada y oro para utilizarlo como gastos de la guerra ${ }^{40}$. Por ello, Montero envió en setiembre a Herrera de nuevo a Puno junto con el batallón Arequipa ${ }^{41}$, pero su misión fracasó por las desavenencias que tuvo con el prefecto Fernandini ${ }^{42}$. Un mes después (25 de octubre), Arequipa caería en manos de las fuerzas chilenas y el gobierno de Montero se disolvería sin pena ni gloria.

¿Qué significaba este retorno de Mesones a las gestiones diplomáticas en un contexto tan complicado y con parte del territorio peruano ocupado por las fuerzas chilenas? La búsqueda del reconocimiento internacional para el gobierno de Montero, como único y legítimo para emprender las acciones necesarias en dos puntos fundamentales, pasaba por la ratificación de la elección de nuevos obispos, en conformidad con el Patronato de 1880, así como por dimensionar con exactitud qué significaría la pérdida de Tarapacá, Tacna y Arica no solo para el Perú sino también para la Santa Sede, como feligreses y parte de la comunidad católica peruana. ¿Qué opinarían los delegados apostólicos? ¿Lo considerarían como un hecho consumado? ¿Eran también de la misma opinión los miembros de la Curia Romana y el Santo Padre? Es decir, a través de aquel nombramiento, Mesones buscaría conseguir alguna adhesión favorable para la causa peruana.

Por otro lado, en ese mismo mes, Iglesias ingresó a Lima como nuevo presidente y firmó el Tratado de Ancón, uno de los documentos más onerosos y lesivos para

37. ACMRE. CC 679. Oficio del Ministerio de Relaciones Exteriores a la Cámara de Senadores del Congreso de Arequipa. Arequipa, 7 de julio de 1883.

38. ACMRE. Caja 283, file 7. Arequipa. 1883. Oficio del Ministerio de Gobierno a la Presidencia del Consejo de Ministros. № 630. Arequipa, 18 de agosto de 1883.

39. ACMRE. Caja 283, file 7. Arequipa. 1883. Oficio del Ministerio de Gobierno a la Presidencia del Consejo de Ministros. № 668. Arequipa, 14 de setiembre de 1883.

40. Sesión de Consejo de Ministros del gobierno de Lizardo Montero. Arequipa, 17 de setiembre de 1883. En: Revista Histórica. Tomo XXXII, p. 144.

41. ACMRE. CC679. Oficio del Ministerio de Relaciones Exteriores al Ministerio de Gobierno. Arequipa, 24 de setiembre de 1883 .

42. Sesión de Consejo de Ministros del gobierno de Lizardo Montero. Arequipa, 17 de octubre de 1883. En: Revista Histórica. Tomo XXXII, p. 145. 
el Perú en su historia (Abanto, 2017a, pp. 154, 214-215). El canciller José Antonio de Lavalle dirigió una circular a todo el cuerpo diplomático extranjero residente en Lima, incluyendo a la Santa Sede, dándoles a conocer el cambio político y la necesidad de reestablecer las relaciones con sus países ${ }^{43}$. Este escenario político fue catastrófico para Mesones, por lo que el cardenal Nina solicitaba a monseñor Sambuccetti, delegado apostólico en Ecuador y Perú, interceder ante el gobierno de Ecuador para que Mesones fuese nombrado diplomático de ese país en España por su destacada participación en el tratado de paz entre el Perú y España, aunque en realidad el mérito fue de Juan Mariano de Goyeneche, jefe de la legación del Perú en Francia (Iannettone, pp. 68-69).

Lavalle dispuso la remoción del personal diplomático del gobierno de Montero y reemplazarlos por otros afines a Iglesias. Este fue el caso de Aurelio García y García, quien fue nombrado a fines de 1883 como jefe de la legación peruana en Inglaterra y tenía una larga trayectoria política y diplomática. Fue marino, diplomático en Japón y China, y secretario general de Piérola en 1881. Posteriormente, el Ministerio de Relaciones Exteriores le encomendó a García y García una nueva misión en Roma, por lo que urgía que presentase sus cartas credenciales en la Corte inglesa ${ }^{44}$.

\section{Mesones en los años de posguerra: Entre la guerra civil, su venida a Lima y retorno a la Santa Sede (1884-1887)}

En febrero de 1884, el Ministerio de Relaciones Exteriores le ordenó a García y García partir hacia Roma para entrevistarse con el cardenal Jacobini, secretario de Estado de su Santidad. Para esos momentos, Manuel Mesones todavía estaba acreditado ante la Santa Sede y había enviado el siguiente cablegrama: «Octubre traslación Bandini Trujillo». Aunque el canciller Mariano Castro Zaldívar desvirtuaría este dato porque esperaba que Roma enviase a un nuevo delegado apostólico para resolver la cuestión eclesiástica en el Perú.

En medio de una nueva guerra civil entre Iglesias y el general Cáceres, Mesones tendría que entregar la misión diplomática ante la Santa Sede a García y García y solicitar la anulación de su nombramiento, así como formalizar la culminación de sus tareas ${ }^{45}$. Si García y García era reconocido en su condición diplomática, facilitaría también el reconocimiento de otras potencias europeas al gobierno

43. ACMRE. CC177. Circular del Ministerio de Relaciones Exteriores a la legación de la Santa Sede en el Perú. Lima, 30 de octubre de 1883.

44. ACMRE. CC 167. Oficio del Ministerio de Relaciones Exteriores a legación del Perú en Inglaterra. № 16. Año 1883.

45. ACMRE. CC 167. Oficio del Ministerio de Relaciones Exteriores a legación del Perú en Inglaterra. $\mathrm{N}^{\circ} 29$. Lima, 24 de marzo de 1884. 
de Iglesias ${ }^{46}$. Luego de instalarse en Roma, García y García inició sus gestiones desde febrero de 1884, logrando cumplir con la delicada misión encargada por el canciller, Baltazar García Urrutia ${ }^{47}$ y que se expresó en este cablegrama: «Gobierno reconocido potencias europeas. Mesones retirado. Pase Roma presentar credenciales perfeccionar arreglo hecho, activar viaje delegado» ${ }^{48}$.

Mesones se uniría rápidamente a los políticos que se oponían a Iglesias en Europa ${ }^{49}$ : Francisco Rosas (exministro plenipotenciario del Perú en Francia e Inglaterra) y José Francisco Canevaro (exministro plenipotenciario del Perú en Italia y Bélgica), sido diplomáticos de la gestión de Montero. El canciller García Urrutia señalaba que Mesones se había unido a estas personas continuando Vsu triste propaganda de noticias adversas al gobierno actual del Perú y sus maquinaciones encaminadas a crearle dificultades de todo género» ${ }^{50}$. Por ello, le pedía a García y García ahondar sus esfuerzos para repeler la propaganda negativa que se hacía contra el gobierno de Iglesias.

García y García logró el envío de un nuevo delegado apostólico al Perú y Ecuador: monseñor Cavichione, quien se instaló en Quito. Su presencia era necesaria para solucionar diversos asuntos eclesiásticos pendientes tras la guerra. Para junio de 1884, todavía no se trasladaba a Lima, por lo que el canciller García Urrutia le pedía a García y García para que verificase la razón de la demora ${ }^{51}$. Asimismo, dada la atención que demandaba su presencia permanente en Roma, se decidió nombrar un nuevo de ministro residente en Inglaterra: José Rafael de Izcue y García y García mantuvo su puesto en la Santa Sede bajo las siguientes razones:

Es de tan vital importancia para las buenas relaciones que debe mantener el Perú con la Santa Sede el éxito seguro de la misión que el gobierno ha encomendado a us (sic) ante el solemne Pontífice y surgen tales conflictos entre la Iglesia y el Estado cuya solución exigirá toda la consagración de la inteligencia y del celo que siempre ha manifestado us (sic) en el servicio de los más altos intereses nacionales que Su Excelencia el Presidente de la República ha resuelto conservar a us (sic),

46 ACMRE. CC 167. Oficio del Ministerio de Relaciones Exteriores a legación del Perú en Inglaterra. No 26. Lima, 24 de marzo de 1884.

47 ACMRE. CC 167. Oficio del Ministerio de Relaciones Exteriores a legación del Perú en Inglaterra. № 32. Lima, 15 de abril de 1884.

48 ACMRE. CC 167. Oficio del Ministerio de Relaciones Exteriores a legación del Perú en Inglaterra. Lima, 6 de mayo de 1884 .

49 ACMRE. CC 167. Oficio del Ministerio de Relaciones Exteriores a legación del Perú en Inglaterra. No 42. Lima, 5 de mayo de 1884.

50 ACMRE. CC 167. Oficio del Ministerio de Relaciones Exteriores a legación del Perú en Inglaterra. No 51. Lima, 21 de mayo de 1884.

51 ACMRE. CC 167. Oficio del Ministerio de Relaciones Exteriores a legación del Perú en Inglaterra. No 18 . Lima, 18 de junio de 1884. 
exclusivamente en nuestra representación en Roma, donde reclaman la presencia constante de us (sic) así sus ya iniciadas gestiones como las que en breve tendrá que presentar a Su Santidad ${ }^{52}$.

¿Qué sucedió con Mesones? Para 1885 se convirtió en agente confidencial del general Cáceres en Roma y lucharía por convertir a su gobierno en un actor beligerante en oposición al de Iglesias, dificultando los planes de García y García. Sin embargo, Mesones tendría que luchar contra los comentarios negativos que lo deslegitimaban ante la Santa Sede, como los rumores sobre su conducta, su origen familiar (hijo fuera del matrimonio) y sus relaciones con el secretario Jacobini ${ }^{53}$ (Iannettone, pp. 76-77). Con la victoria electoral de Cáceres en 1886, Mesones regresó a Lima y fue elegido diputado por Pataz (Tuesta, p. 177), formando parte de la Comisión Diplomática junto con Manuel María del Valle (exministro del Perú en Bolivia), Mariano Nicolás Valcárcel (excanciller), Francisco E. Tagle, José M. Suárez ${ }^{54}$.

Sin embargo, ese retorno sería efímero porque el presidente Cáceres lo nombró nuevamente jefe de la legación peruana en la Santa Sede el 16 de noviembre de 1886 y arribó a Roma en febrero de 1887. Esta vez, su regreso a Europa fue distinto, porque el secretario de Estado y familiar suyo, cardenal Jacobini, murió en marzo de 1887. Mesones presentó sus credenciales en julio, pero quedó desprotegido sin Jacobini y no tardaron en presentarse problemas como el nombramiento de nuevos obispos para el Perú, que lo obligaron finalmente a renunciar a fines del mismo año ${ }^{55}$. Ante su renuncia, fue nombrado Juan Mariano de Goyeneche, quien ya había tenido el mismo cargo en la Santa Sede en 1879 y tenía una estrecha relación con la oligarquía y jerarquía eclesiástica arequipeña, con diversos títulos nobiliarios y con fuertes vínculos en Europa, en especial con España.

Goyeneche tomó como referencia la experiencia desarrollada por la familia Mesones en Roma; es decir, aprovechó las complejas redes familiares y relaciones sociales para tener el control de la legación peruana en la Santa Sede durante la segunda mitad siglo XIX. Goyeneche estaría en el cargo entre 1887 y 1920, es decir, casi más de 40 años de control de la legación y que luego se convertiría en la

52 ACMRE. CC 167. Oficio del Ministerio de Relaciones Exteriores a legación del Perú en Inglaterra. Reservada. No 100. Lima, 30 de setiembre de 1884.

53 Oficios del agente confidencial del Perú en la Santa Sede. N. ${ }^{\circ}$ 1, 2, 3, 5, 7, s/n. Roma, 10 de febrero, 10 de marzo, 14 de abril, 15 de abril y 28 de diciembre de 1885. En Iannettone (2007). Relaciones entre el Perú y la Santa Sede en el tiempo de los Mesones (1859-1887). Pp. 241-248.

54 http://www4.congreso.gob.pe/comisiones/1999/exteriores/Libroweb/cap1.html Consultado el 27 de julio de 2020.

55. Oficios del ministro residente del Perú en la Santa Sede N. ${ }^{\circ}$ 1, 2, 3, 4, 5, 6, 7, 10. Roma, 16 de noviembre de 1886, 14 de febrero, 7 de marzo, 25 de julio, 24 de agosto y 7 de octubre de 1887. En Iannettone (2007). Pp. 249-253, 260-265. 
embajada del Perú en el Vaticano (Mamani, 2018, p. 54). Cabe mencionar que los resultados de sus gestiones siguen siendo un estudio pendiente, tomando en cuenta que estos ocurrieron en un contexto particularmente convulsionado como la Primera Guerra Mundial.

Fotografía 8. Juan Mariano de Goyeneche

Ministro plenipotenciario y enviado extraordinario del Perú en la Santa Sede. 1886-1900

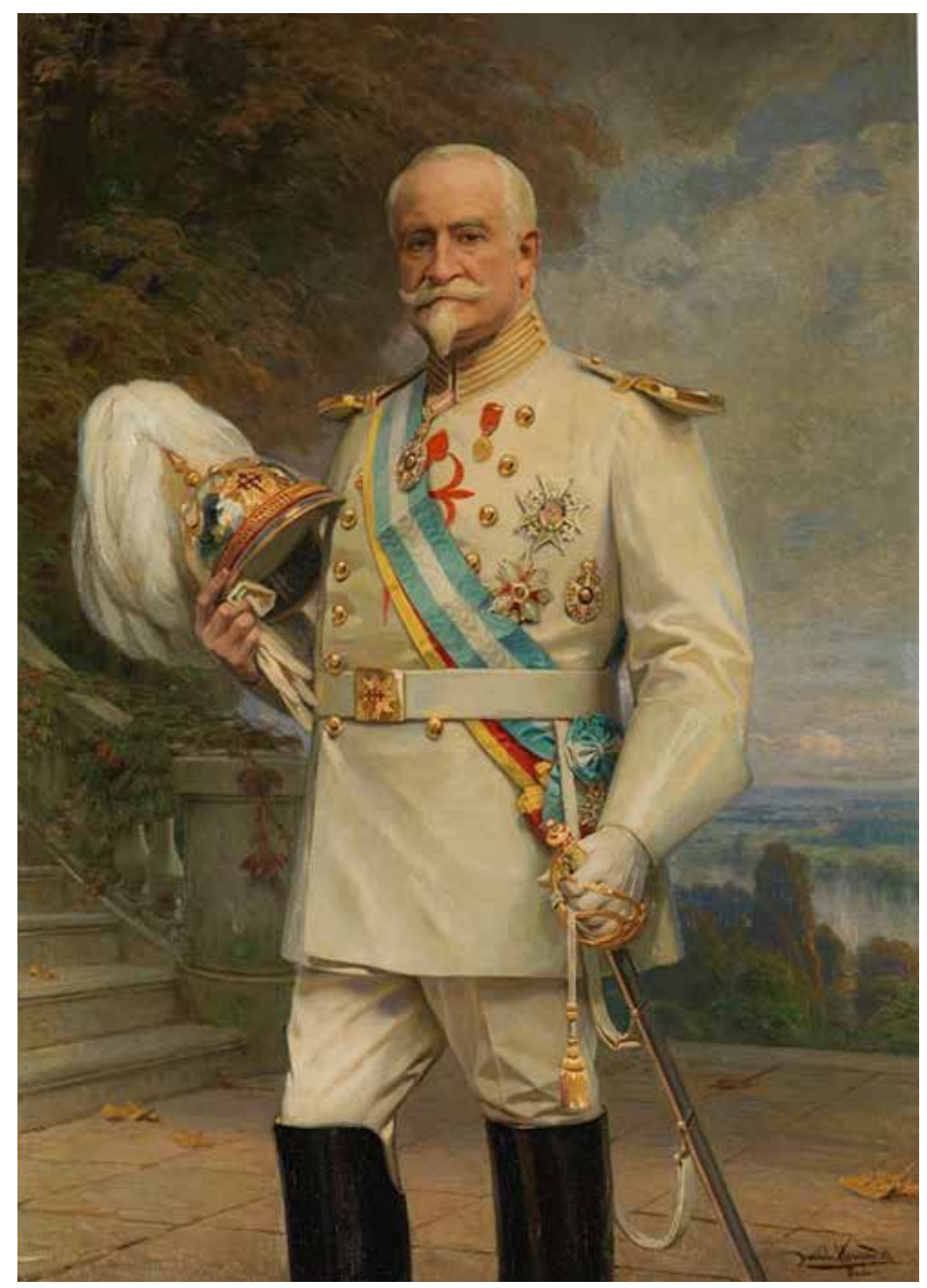

Fuente: Museo del Prado

https://www.museodelprado.es/coleccion/obra-de-arte/juan-mariano-de-goyeneche-y-gamioiii-conde-de/44dac9d4-f5df-4a1a-8764-63bb7adb0f48 


\section{Conclusiones}

La historia de la Iglesia en el Perú tiene aún aspectos no examinados por la historiografía, uno de ellos es el análisis de las relaciones diplomáticas entre la Santa Sede y el Perú en la segunda mitad del siglo XIX. Por esta razón, el artículo se centró en realizar un estudio descriptivo que permitiese reconstruir la dinámica diplomática que establecieron ambos Estados. Esto llama la atención en la medida que la Iglesia tuvo un importante rol económico y político antes y después de la Guerra del Pacífico; incluyendo su influencia en la dinámica de la política exterior y otros escenarios que muestran el papel de las relaciones de la Iglesia en la consecución de los objetivos del Estado peruano. En esta dinámica también participan entidades como el Ministerio de Relaciones Exteriores, la legación del Perú en la Santa Sede, la Iglesia peruana, la Secretaría de Estado en Roma y la delegación Apostólica en América del Sur, específicamente, en temas como el nombramiento y ratificación de obispos (Patronato), entre otros.

En ese sentido, tras integrar la información bibliográfica y de fuentes históricas procedentes del Ministerio de Relaciones Exteriores, se pudo observar el papel gravitante de la familia Mesones en la gestión de la legación en diferentes épocas: Luis Mesones (1859-1861, 1865) y Manuel Mesones (1882-1887). Para mantenerse en el control de los cargos diplomáticos, apelaron a diversas redes familiares (padre-hijo) y sociales (Manuel Mesones con el secretario de Estado, monseñor Jacobini) quienes animaron la construcción de una imagen de influencia en los asuntos de la Santa Sede, como el nombramiento de obispos peruanos y otros asuntos eclesiásticos. Esta misma dinámica la utilizará también Juan Mariano Goyeneche entre 1887 y 1920.

Asimismo, queda pendiente una información a profundidad sobre la propuesta de Chocano (2010) con relación al apoyo recibido por la Iglesia como el arzobispo de Lima en el Consejo de Estado (1880), durante la dictadura de Piérola en oposición a los liberales y masones que formaban parte del civilismo. Además, conocer las motivaciones del obispo Tordoya para involucrarse en la conducción de la Delegación de Lima (1882-1883), representando al gobierno de Montero, y porque este puesto clave de la administración pública no recayó en el arzobispo de Lima. 


\section{Referencias bibliográficas}

Abanto, J. (2012). Encarando el desastre. El conflicto hegemónico entre la burguesía limeña y los terratenientes serranos del norte durante la guerra con Chile (1881-1883). Lima: Universidad Nacional Mayor de San Marcos.

Abanto, J. (2017a). El Congreso de la República durante la ocupación chilena: Chorrillos, Ayacucho, Cajamarca y Arequipa. Lima: Ediciones del Rabdomante.

Abanto, J. (2017b). La actividad de la delegación de Lima en el contexto de la ocupación chilena de la capital (1881-1882). Revista Del Archivo General de la Nación. 1(32), 181-196.

Armas, F. \& Monsalve M. (2019). La memoria de Manuel de Argumaniz. Un empresario peruano del siglo XIX. Lima: Universidad del Pacífico.

Armas, F. (2007). Iglesia: bienes y rentas. Secularización liberal y reorganización patrimonial en Lima 1820-1950. Lima: Instituto de Estudios Peruanos.

Armas, F. (2001). Financiar la guerra: planes fiscales, lucha política y crisis inflacionaria en el Perú. Revista Histórica. 2(15), 49-97.

Basadre, J. (1964). Historia de la República. T. VIII. Lima: Editorial Universitaria.

Camprubí, C. (1957). Historia de los bancos en el Perú. Lima: Editorial Lumen.

Chaupis, J. (2012). El califa en su laberinto: esperanza y tragedia del régimen pierolista. Lima: Seminario de Historia Rural Andina de la Universidad Nacional Mayor de San Marcos.

Chocano, M. (2010). Lima masónica: las logias simbólicas y su progreso en el medio urbano a fines del siglo XIX. Revista de Indias 70(249), 409-444.

Cordero, C. (2020). El papel de la Iglesia limeña durante la guerra con Chile. Una aproximación a las cartas pastorales y las oraciones fúnebres (1879-1883). Discursos Del Sur (5), 147-162.

De la Puente Candamo, J. \& De la Puente Brunke, J. (Eds.) (2008). El Perú desde la intimidad. Epistolario de Manuel Candamo (1873-1904). Lima: Pontificia Universidad Católica del Perú.

De la Puente Candamo, J. \& De la Puente Brunke, J. (Eds.) (2016). El Estado en la sombra. El Perú durante la ocupación chilena. Documentos administrativos (diciembre de 1881-julio de 1882). Lima: Pontificia Universidad Católica del Perú.

De Roux, Rodolfo R. (2014). La romanización de la Iglesia católica en América Latina: una estrategia de larga duración. Pro-Posições 25(1-73), 31-54.

Denegri, F. (1979-1980). Cartas del general Prado al general La Puerta. Revista Histórica 32, pp. 213-376.

Gálvez, J. \& García, E. (2016). Historia de la Presidencia del Consejo de Ministros. Democracia y buen gobierno (1820-1956). Tomo I. Lima: Empresa Peruana de Servicios Editoriales. 
García Jordán, P. (1998). Estado moderno, Iglesia y secularización en el Perú contemporáneo. Revista Andina 6(2), 51-401.

Guice, N. (1984). Crónicas de la Guerra con Chile (1881-1883). Lima: Mosca Azul editores.

Guzmán, L. (1990). Campaña de la Breña. Colección de documentos inéditos. 1881-1884. Lima: Centro de Estudios Históricos Militares del Perú.

Holguín, O (1972). Aspectos de la vida religiosa en Lima durante la ocupación chilena (1881-1883). Boletín del Instituto Riva-Agüero (9), 168-171.

Iannettone, G. (2007). Relaciones entre el Perú y la Santa Sede en el tiempo de los Mesones (1859-1887). Roma: Ediciones del autor.

Klaiber, J. (1996). La Iglesia en el Perú. Lima. Pontificia Universidad Católica del Perú.

Luna, J. (1979-1980). Libro de actas del Consejo de Ministros (1875-1879). Revista Histórica 32, 9-97.

Mamani, R. (2018). Grupo económico familiar los Goyeneche. II Dinastía 1872- 1950 (tesis de pregrado). Universidad Nacional San Agustín de Arequipa, Arequipa.

Martín, J. (1973-1975). Jesuitas del Perú en la Guerra del Pacífico. Cuadernos del Seminario de Historia (11), 5-11.

Ministerio de Justicia y Derechos Humanos (2016). Relaciones entre la Santa Sede y la República del Perú. Marco normativo. Lima.

Ministerio de Relaciones Exteriores (1862, 1878, 1885,1888). Memorias presentadas al Congreso de la República. Lima: Ministerio de Relaciones Exteriores.

Nieto, A. (1979-1980). Vicisitudes del gobierno provisional de Arequipa (1882-1883). Revista Histórica 32, 99-147.

Nieto, A. (1983). La Iglesia en 1879. En torno a la Guerra del Pacífico, 149-168.

Paz Soldán, P. (1891). Páginas diplomáticas del Perú. Lima: Imprenta de la Escuela de Ingenieros.

Rubio, R. (1980). Acerca de las relaciones entre la Iglesia y el Estado peruano. Revista de la Universidad Católica (80), 109-135.

Tuesta, Fernando (2001). Perú político en cifras. Lima: Fundación Friedrich Ebert.

Valdez, F. (2004). Las relaciones entre el Perú e Italia (1821-2002). Lima: Pontificia Universidad Católica del Perú.

Valle, M. (2013). Relaciones entre chilenos y mujeres peruanas residentes en Lima durante la ocupación militar de la ciudad (1881-1883) a través de las fuentes parroquiales (Tesis de pregrado). Pontificia Universidad Católica del Perú, Lima

Vargas, R. (1939). Aspecto histórico del nombramiento de obispos en el Perú. Revista de la Universidad Católica 7(2-3), 127-140. 


\section{Fuentes consultadas}

Archivo Central del Ministerio de Relaciones Exteriores

Cuadernos copiadores Años 1879-1883

CC 126, CC 133, CC 139. Cuadernos copiadores de correspondencia dirigida a las legaciones peruanas en el exterior. Año 1879.

CC 158. Cuaderno copiador de correspondencia dirigida a las legaciones de los países europeos. Años 1882-1883.

CC 167. Cuaderno copiador de correspondencia dirigida a las legaciones peruanas en Londres, Francia y los Estados Unidos. Año 1883.

CC 679. Cuaderno copiador de correspondencia dirigida al Congreso de la República. Año 1883.

\section{Correspondencia}

Correspondencia del Ministerio de Relaciones Exteriores. Comunicaciones de los agentes confidenciales al Ministerio de Relaciones Exteriores. Caja 282. Carpeta 17. Código 7-13. Año 1882.

Correspondencia del Ministerio de Relaciones Exteriores. Código 1-5. Caja 283, file 7. Oficios del Congreso de la República del Perú a la PCM y Ministerio de Relaciones Exteriores. Año 1883.

\section{Biblioteca Nacional del Perú}

Archivo Piérola: Sobres: 5000000796, 5000000831, 5000000857, 5000000859.

Colección Manuscritos: Libro de actas públicas del Consejo de Estado. Año 1880. Documento 2000022357. 